REVISTA DE DERECHO UNED, núm. 1, 2006

\title{
EL SENADO ESPAÑOL ANTE EL RETO DE INTERNET
}

\author{
JosÉ JuLIo FERnÁNDEZ RodRíGUEZ
}

Sumario: I. INTRODUCCIÓN.-II. PODERES PÚBLICOS Y SOCIEDAD DE LA INFORMACIÓN.-III. LAS ASAMBLEAS REPRESENTATIVAS ANTE INTERNET.-IV. MEDIDAS ADOPTADAS.-V. INFORMES Y COMISIONES.-VI. CONCLUSIONES.

\section{INTRODUCCIÓN}

El vertiginoso progreso técnico de los últimos años ha tenido múltiples incidencias en campos muy diversos, entre los que se encuentra el marco de actuación de los órganos públicos. Se hace necesario, pues, analizar las respuestas que deben dar estos últimos al nuevo contexto que nos ofrece el siglo XXI con el objeto de que puedan cumplir mejor las funciones que el ordenamiento jurídico democrático les asigna. Ello no deja de ser una exigencia lógica dimanada del principio de eficacia.

La Sociedad de la Información y su estandarte, Internet, generan particulares exigencias para el sistema público, que debe necesariamente adaptarse y aprovechar las nuevas posibilidades para seguir sirviendo de forma adecuada a la comunidad. Se ha dicho, incluso, que el mundo digital está originando la aparición de un nuevo estadio en la evolución humana, el "Infolítico», en el que no se trabaja con átomos sino con realidades intangibles. De este modo, se trata de subrayar la mutación de categorías y de pautas culturales a las que tiene que enfrentarse la persona con la digitalización de lo que le ro- 
dea y con su inmersión en la Sociedad de la Información ${ }^{1}$. Surgen, así, cambios cualitativos y cuantitativos, que afectan a nuestra propia existencia, aunque con más intensidad en las áreas de mayor desarrollo (lo que, por cierto, es una de las manifestaciones de la denominada brecha digital). La tradicional diferencia entre lo público y lo privado se difumina en la Red surgiendo, de esta forma, un espacio nuevo, que nosotros hemos llamado en otro lugar «lo neopúblico» ${ }^{2}$, una nueva manera de reflejarse lo público sin masas a través de un conjunto de usuarios conectados digitalmente en una recreación de «realismo» virtual.

En esta tesitura, y en comparación con otros órganos, el Senado español ha sido especialmente sensible al reto de Internet y de las tecnologías de la información y comunicación, como lo prueban las medidas y actuaciones que comentamos más abajo.

Internet favorece el funcionamiento del proceso democrático desde diversos puntos de vista al jugar a favor del pluralismo y la participación en un sentido que va más allá de la simple lógica electoral. La Red no es sólo la tecnología de la libertad sino también tecnología de la democracia. Como afirma Castells, los principales factores inductores de "la transformación de la política y de los procesos democráticos en la sociedad red" vienen dados por "las consecuencias directas de las nuevas tecnologías de la información sobre el debate político y las estrategias de búsqueda del poder» ${ }^{3}$.

\section{PODERES PÚBLICOS Y SOCIEDAD DE LA INFORMACIÓN}

Los poderes públicos están llamados a desempeñar una importante función en el terreno de la Sociedad de la Información y, por ende, en Internet. Por un lado en el campo de la regulación, aunque, eso sí, no para articular medidas represoras de la libertad individual, sino proteccionistas y garantes de la libertad de expresión y de

1 También hay voces contrarias a estas ideas, que las califican de determinismo técnico (WOLTON, Dominique, Internet ¿y después?, Gedisa, Barcelona, 2000), lo cual es cierto en algunos casos, pero no en otros en los que la técnica moderna conlleva mutaciones culturales, o sea, altera las pautas de referencia que permiten al ser humano ubicarse en su contexto.

2 FERNÁNDEZ RODRÍGUEZ, José Julio, Lo público y lo privado en Internet. Intimidad y libertad de expresión en la Red, Universidad Nacional Autónoma de México, México D. F, 2004, págs. 181 y ss.

${ }^{3}$ CASTELLS, Manuel, La era de la información. Vol. 2. El poder de la identidad, Alianza, Madrid, 1998, pág. 342. 
la intimidad de los navegantes. El aparato estatal no puede diluirse en este punto puesto que, como afirma Lessig, «la libertad en el ciberespacio no surgirá de la ausencia de Estado", sino precisamente de la mano del mismo .

Con el paso del tiempo, desde unos orígenes más libertarios, el papel de los poderes públicos ha ido creciendo en intervencionismo ante el fenómeno de Internet, sobre todo en Europa. Incluso, el gobierno estadounidense, que nunca dejó de impulsar y controlar el fenómeno, asumió un rol más activo de coordinación desde finales del siglo XX. La creciente importancia mercantil de la Red es la causa principal de este cambio de actitud. No obstante, los intentos del control en Internet siempre han encontrado importantes dificultades para alcanzar plena eficacia habida cuenta sus características ${ }^{5}$.

Desde un plano de lege ferenda, los órganos públicos no deben buscar el control sino la garantía del desarrollo de la actividad en términos igualitarios, de eficacia y de universalidad del acceso. Esta es la línea de las políticas de impulso que en ocasiones muy diversas ya se han adoptado. Los poderes públicos deben llevar a cabo campañas de información y divulgación que toquen distintos aspectos, como, por ejemplo, las opciones técnicas de seguridad informática, la promoción de productos seguros y los derechos que asisten al usuario. Esto significa que no se puede prescindir del papel del sector público como garante en último término de las libertades en Internet, lo que no comporta que haya que descuidar el sector privado, que también está llamado en este terreno a desempeñar su papel y a asumir responsabilidades comunitarias a través de mecanismos de autorregulación.

\section{LAS ASAMBLEAS REPRESENTATIVAS ANTE INTERNET}

Las asambleas representativas se enfrentan a una serie de problemas que hunden sus raíces en la tan repetida expansión del Poder Ejecutivo, fortalecido con la mayoría parlamentaria gubernamental, y en las rémoras de adecuación a una realidad tan dinámica y cambiante como es la actual, que mezcla Estado Social, neolibera-

${ }^{4}$ LESSIG, El Código y otras leyes del ciberespacio, Madrid, 2001, pág. 23

5 Por eso afirma CASTELLS que es una batalla perdida la lucha futura de los Estados "para controlar la circulación de la información en las redes de telecomunicaciones interconectadas a escala global» (CASTELLS, Manuel, La era de la información, vol. 2: el poder de la identidad, Alianza, Madrid, 1998, pág. 287). 
lismo y Sociedad de la Información, entre otros fenómenos. Este contexto genera nuevas legitimidades que inciden en la representatividad de las cámaras legislativas. La política simbólica y la seducción (engañosa) de la democracia de la identidad o directa avanza en contra de las estructuras representativas. Es en esta sensación de cierto anquilosamiento donde Internet puede jugar un papel de reactivo que mejore la posición de las cámaras parlamentarias. Así lo entiende Pau i Vall cuando afirma que las nuevas tecnologías suponen un reto a la actualización de las instituciones parlamentarias ${ }^{6}$. Y, de igual modo, Tudela Aranda, ve "plausible pensar que las nuevas tecnologías y, en concreto, Internet, pueden irrumpir en auxilio» del Parlamento ${ }^{7}$. El Parlamento, en suma, no debe perder la centralidad del debate político.

En este sentido, la Unión Interparlamentaria, años atrás, ya había percibido la virtualidad de las nuevas tecnologías, y en la Resolución adoptada el 15 de septiembre de 1997 en El Cairo, en la $98^{\mathrm{a}}$ Conferencia de dicha organización, «demande aux Etats de garantir en permanence l'accès illimité des citoyens à l'éducation et à l'information et, à cet égard, souligne l'utilité des nouvelles technologies pour le travail des parlements». Asimismo, por todo el mundo, especialmente en los países democráticos, las cámaras han ido elaborando sus páginas web, si bien con una finalidad preferentemente descriptiva e informativa, que no deja de ser de indudable interés para toda la ciudadanía. Este interés crecerá a medida que las páginas se sofistiquen y se introduzcan en el camino de la multidireccionalidad. De igual modo, los grupos parlamentarios y muchos diputados ya poseen páginas propias, a las que hay que añadir sus direcciones de correo electrónico. Estos instrumentos pueden llegar a potenciar la figura del representante frente al dominio del grupo parlamentario y, por ende, del partido, lo que es más acorde con las exigencias del mandato representativo. Lo dicho reclama una precisión a mayores. La introducción de las nuevas formas de comunicación de Internet en la dinámica parlamentaria conlleva la exigencia de realizar los esfuerzos oportunos para su correcto mantenimiento y supervisión, porque de poco sirven los instrumentos citados si su contenido no está actualizado ni se revisa.

" PAU I VALL, Francesc, "Democracia e Internet", Anuario de Derecho Constitucional y Parlamentario, núm. 10, 1988, pág. 195.

7 TUDELA ARANDA, en CAYÓN GARRIDO, Antonio (coord.), Internet y Derecho. Monografías de la Revista Aragonesa de Administración Pública, Gobierno de Aragón, Zaragoza, 2001, pág. 64. 
Llegados a este punto de la evolución parece imprescindible superar el estadio de la mera descripción e implementar vías interactivas para que los ciudadanos hagan llegar su voz al Parlamento y que la relación de éste con el pueblo no sea unidireccional. Por medio de la interactividad de la Red el pueblo puede ejercer diversas actividades de control de la actividad política y convertir a las cámaras en crisol de participación ciudadana. Una participación que encuentra salidas muy diversas gracias a Internet, que van desde comparecencias en comisiones hasta una articulación digital del derecho de petición, pasando por la instauración de foros como los ya experimentados en el Bundesrat alemán o en el Senado español. No obstante, semeja conveniente no perder la prudencia a la hora de ofrecer soluciones técnicas como las referidas para no caer en la saturación, siempre disfuncional, lo que obliga a hacer una adecuada ponderación de los medios, los fines y las posibilidades reales. El Informe de la Comisión Especial sobre Redes Informáticas del Senado español, de 17 de diciembre de 1999, sobre el que volvemos más abajo, señala en este orden de ideas que «las instituciones parlamentarias utilizarán las redes electrónicas para aproximar las relaciones entre representantes y representados, facilitando la participación activa y directa de los españoles en sus actividades y procedimientos».

El Parlamento tiene que estar cerca de la sociedad y de sus ciudadanos para colmar sus ansias de legitimidad habida cuenta que las elecciones periódicas no lo aportan todo, aunque sí, hay que reconocerlo, la mayor parte. Las asambleas deben vehicular a la opinión pública hacia el sistema democrático y ser el faro político principal que alumbre a la ciudadanía.

Internet es una gran ayuda para el ejercicio de la función parlamentaria de información, al tiempo que proporciona una batería de instrumentos para compensar el desequilibrio con el Poder Ejecutivo. La inmediatez con la que se puede trabajar en la Red aporta valor añadido a esa labor de información, imprescindible para la adecuada construcción de la opinión pública y vital para conseguir la permeabilidad de la institución. Esta mejora de la información es beneficiosa para la capacidad de comunicación política de los parlamentos, en gran parte pisada por los medios de comunicación de masas. Éstos actúan con determinados sesgos ideológicos y a golpe de intereses mercantiles, por lo que la mejora de la información de las cámaras se nos antoja doblemente interesante desde los postulados del pluralismo y desde la eliminación de intermediarios. No en vano, como se ha dicho, «la información es la materia prima de una sociedad demo- 
crática ${ }^{8}$. La tarea de llegar a la información no sólo se facilita a la ciudadanía sin también a los propios parlamentarios, tanto durante las sesiones como en otro momento cuando quieran consultar, por ejemplo, un proyecto de ley, un diario de sesiones o un discurso de algún compañero de la Cámara. La función legislativa, por su parte, se ve mejorada con la incorporación de nuevas vías de participación en el procedimiento de elaboración de normas. Esto lleva a Tudela Aranda a considerar "recomendable que los parlamentos introduzcan en sus procedimientos legislativos una fase anterior de consulta a colectivos sociales y que éstas se articule, básicamente, a través de la Red ${ }^{9}$. De igual modo, resulta evidente el papel destacado que puede jugar Internet en la articulación de la iniciativa legislativa popular.

Estas ventajas que estamos vislumbrando son de particular interés en las cámaras territoriales pues Internet permite que las mismas cumplan mejor con la especificidad de sus funciones. La reducción de distancias que impone la tecnología digital facilita la representación de territorios alejados del lugar donde se ubica la Cámara Alta y la agregación de estos intereses territoriales se ve facilitada con Internet.

La Red, además de lo dicho y en la línea del párrafo anterior, acerca y conecta a los diversos parlamentos entre sí, lo que es un dato relevante en Estados de estructura compleja donde el poder esté distribuido territorialmente hasta tal punto que existan diversas cámaras legislativas, que, aunque operen sobre marcos competenciales diferentes, no dejan de estar integradas en el mismo Estado. También Internet ayuda en los procesos de integración supranacional vinculando a las cámaras de los distintos Estados implicados en semejante proceso, colaborando, así, en la creación de afinidades, dinámicas similares y posos de cultura política compartida (sin elementos comunes se nos antoja imposible la correcta evolución de un proceso de integración supranacional). En Europa esto es particularmente interesante dadas las críticas de falta de legitimidad democrática que se esgrimen contra las instituciones comunitarias europeas.

Con las nuevas tecnologías en general, y con Internet en particular, la labor y el papel de las instituciones parlamentarias adquieren nuevos bríos y posibilidades, lo que redundará de manera positiva en

${ }^{8}$ ALEXANDER, Kim, en PAU I VALL, Francesc (coord.), El Parlamento del siglo $X X I$, Tecnos, Madrid, 2002, pág. 90.

9 TUDELA ARANDA, en CAYÓN GARRIDO, Antonio, Internet y Derecho op . cit., pág. 86. 
el conjunto del sistema político, que se ve refrescado con dosis de agilidad, transparencia y permeabilidad. Esto se debería percibir con especial intensidad en las cámaras de representación territorial. Ello se enmarca en una idea más amplia, que es la de la mejora de las tareas de gobierno en un sentido amplio.

\section{MEDIDAS ADOPTADAS}

La implicación del Senado en la informática comienza con la creación en enero de 1987 de la Dirección de Informática, lo que generó inicialmente inquietud en los usuarios, aunque pronto se percataron del positivo papel que podían jugar las tecnologías digitales. Se empezó con una informática centralizada, basada en un sistema propietario que comprendía un ordenador central (mainframe), un miniordenador para las comunicaciones y una serie de pequeñas redes ofimáticas. Después se pasaría a lo que se denomina informática distribuida. Parece percibirse desde estos inicios el intento de estar al día en las continuas innovaciones, si bien fijándose en sistema consolidados y evitando las fluctuaciones del mercado y lo que Javier De Andrés califica acertadamente de "espejismos tecnológicos" ${ }^{10}$. Desde estos comienzos siempre se han enfatizado las cuestiones relativas a las comunicaciones, en un triple sentido: con el Congreso de los Diputados, con las Asambleas Legislativas de las Comunidades Autónomas y con otros órganos institucionales. Asimismo, se priorizó la comunicación de datos para lograr la correcta difusión de los contenidos de las bases de datos legislativas.

Como se señala en la página web acabada de citar, en este marco se ha dado una especial importancia al fenómeno de Internet desde mayo de 1993 cuando se celebran en Granada las III Jornadas sobre tecnologías de la información para la modernización de las Administraciones Públicas. El salto cualitativo se produjo con la aparición de su página web.

Las páginas web se han convertido en la carta de presentación de los órganos públicos ante el reto de Internet. A través de las mismas se trata de vehicular tanto la imagen de la institución ante la sociedad como la explicación del papel y funciones asignadas, además de diversa cantidad de información. Ello es más patente en las páginas web de los parlamentos por la especial tesitura en que se encuentran

${ }^{10}$ www.epitelio.org/cuenca/encuentros/senado.htm (consulta en noviembre de 2005). 
y por las virtualidades que para los mismos supone la Red. Además, ya muchos representantes políticos tienen páginas personales con las que tratan de mejorar su comunicación con los representados y de publicitar su labor particular (es éste un asunto muy interesante pero en el que ahora no podemos detenernos para no desviar nuestro hilo argumental).

La página web del Senado se encuentra en la dirección www.senado.es $^{11}$. Su incorporación a Internet data del 17 de noviembre de 1997. Se diseñó y concibió como un instrumento de información sobre la Cámara Alta en cuestiones diversas. Poco a poco ha intentado perder esa visión unilateral inicial y avanzar hacia la bi y multilateralidad, aunque con muchos deberes todavía por cumplir en esta tarea.

Dicha página (en noviembre de 2005) tiene tres partes: un esquema de hipervínculos a la izquierda, un conjunto de información central y una barra inferior que remite a un tema en concreto (por ejemplo, al debate sobre la situación del Estado de las Autonomías, celebrado el 7, 8 y 9 de noviembre de 2005, o a las Jornadas de Puertas Abiertas, el 30 de noviembre y el 1 y 2 de diciembre de 2005). En la actualización de 2 de agosto de 2006 esta barra inferior ya no consta (tal vez las vacaciones estivales aconsejaron su simplificación).

Los ítems de la izquierda son los siguientes: presidente (saludo y encuentro virtual), mapa de la web, buscador, canal Senado, foros, visita virtual y versión sólo texto. En la parte superior de este listado se encuentra el escudo del Senado y la referencia al número de legislatura en la que nos encontramos (ahora la octava). Debajo de los ítems señalados se ubican dos hipervínculos: uno para enviarle un mail al webmaster (webmaster@senado.es), y otro para acceder a la página web en inglés.

La información central de la página se agrupa en cuatro partes: «Qué es», "Cómo funciona», "Qué hace», y «Para saber más». Cada una de ellas tiene varios hipervínculos que en conjunto ofrecen una muy amplia información. Al acceder a cada uno, en segundo nivel, al margen de la información propia de cada subtema, existe una barra horizontal superior por la que se accede a una selección de los hi-

11 Otras páginas que se pueden citar a título de ejemplo de cámaras altas son www.seante.gov, www.bundesrat.de, www.senat.fr, www.senato.it, www.eerstekamer.nl, www.senat.gov.pl, www.senat.cz, www.council.gov.ru, www.senat.ro, www.senado.gov.ar, www.senado.bo, www.senado.gov.br, www.senado.cl, www.senado.gov.co, www.senado.gov.mx, www.senado.gov.py. A través de su consulta el lector podrá hacerse una perfecta composición de lugar de lo que se está haciendo en otros lugares en este punto. 
pervínculos de esta parte central de la página: «senadores», «órganos rectores", "comisiones", "sesiones plenarias", «iniciativas legislativas», "publicaciones oficiales» y «agenda semanal». Da la impresión que esta barra selectiva de información trata de condensar lo que los autores de la web consideran más relevante.

El número de visitas al mes que se nos ha indicado, en noviembre de 2005 , es de $250 \mathrm{mil}$. A la actualización se le presta especial atención, lo que sorprendentemente no siempre ocurre en páginas de organismos públicos. Los contenidos procedentes de bases de datos se actualizan dos veces al día, una al mediodía y otra por la noche; y las convocatorias de las comisiones se visualizan en tiempo real, es decir, aparecen en la Red en el momento en que se cargan los datos de la reunión de que se trate.

En conjunto, la página es completa desde el punto de vista de la información, por lo tanto resulta útil, además de actualizarse con corrección. Sin embargo, peca de falta de agilidad y, en cierto sentido, funcionalidad al carecer de elementos eficaces de selección cualitativa de información. Parece que se está trabajando en su mejora y en dotarla de un aspecto más dinámico y moderno que elimine la sensación de pesadez que tiene ahora, rasgos que ya están presentes en otras webs, como www.administración.es, o www.justicia.es.

Es de reseñar la existencia en la página de un Encuentro virtual con el Presidente del Senado, en el que es posible formular preguntas y en donde también se encuentran las respuestas a las mismas. El tipo de preguntas, como se imaginará, es de lo más variopinto, aunque llama la atención el elevado número de las mismas (con relación a otras iniciativas similares que existen en otros órganos públicos). A este espacio, según la presentación que hace el propio Presidente, los ciudadanos pueden enviar "preguntas, comentarios, dudas o sugerencias sobre el Senado, su funcionamiento, los contenidos de las propuestas que aquí se debaten o (...) sobre asuntos relacionados con la actualidad diaria» ${ }^{12}$. Javier Rojo se compromete a responder cada mes y a publicar las respuestas en la web del Senado. Con este foro, el Presidente de la Cámara pretende «estar más cerca de las inquietudes de los ciudadanos y, de esta forma, poder entablar una comunicación fluida» con los internautas. Termina diciendo que así se pretende acercar, en la medida de lo posible, «esta institución, que es la casa de todos vosotros, a la ciudadanía y que entre todos hagamos

${ }^{12}$ http://www.senado.es/presidente/presidente virtual2.htm (consulta el 9 de noviembre de 2005). 
posible un mayor conocimiento y una mayor participación ciudadana en el ámbito de la política y, más concretamente, en todo lo relacionado con la Cámara Alta».

En cuanto a los foros que se ofrecen en la web en la actualidad sólo tenemos el foro de la Comisión de la Sociedad de la Información y del Conocimiento, al que se alude más abajo.

En la VI Legislatura hubo otro foro en la "Comisión Especial sobre Redes Informáticas», al que también nos referimos más adelante. Asimismo, con motivo de la celebración del Día de la Constitución en 1999, y coincidiendo con las Jornadas de Puertas Abiertas (el 1, 2 y 3 de diciembre) se habilitó un foro para que se expresaran opiniones sobre temas relacionados con las competencias del Senado. En éste se recogieron 60 intervenciones.

Los foros, adecuadamente usados, son un instrumento de elevada virtualidad democrática. En una institución representativa permiten que se produzca un segundo debate que complementa al debate principal que se produce entre los integrantes de la misma. Aparecen, de este modo, dos espacios de discusión, uno real y otro virtual, enriqueciéndose la percepción de los problemas estudiados. Sin embargo, la funcionalidad del segundo, el virtual, aún está consolidándose mientras la ciudadanía se socializa en el entorno de las nuevas tecnologías. Quizá en el futuro este tipo de foros puedan reconstruir la democracia representativa, pero en la actualidad ello todavía no se ha producido.

De igual forma, es relevante la existencia del denominado Canal Senado, que tiene un link, como se dijo, en la web. Se trata de un canal de televisión producido por el Senado con el fin de alcanzar «una mayor difusión y un mejor conocimiento de la actividad de la Cámara». En principio, se transmiten en directo las sesiones del Pleno y de diversas comisiones. La emisión se produce tanto por Internet como por satélite. Para la Red es necesario disponer del reproductor RealPlayer (se proporciona una página de ayuda para descargar, instalar y configurar dicho reproductor). La emisión satelital se efectúa en abierto por el Hispasat.

También, en este apartado, parece conveniente hacerse eco de algunas declaraciones que inciden en el tema de Internet. No tendría sentido ahora referirnos a ellas de manera pormenorizada, simplemente apuntamos alguna que le permitan al lector hacer una comprensión cabal del tema. Por ejemplo, el presidente del Senado, el ya citado Javier Rojo, afirma en el saludo que consta en la web lo siguiente: "Os animo a que visitéis esta página web y nos conozcáis un 
poco mejor a todos los que desempeñamos nuestra labor en esta Cámara». A lo que añade: «En ella podréis encontrar las iniciativas de los distintos Grupos Parlamentarios, los debates en el Pleno de la Cámara Alta y los acuerdos que en ella se alcancen». El propio Presidente del Senado reitera la invitación a participar a través de Internet en la presentación que hace del «Encuentro virtual» antes comentado. Como vemos, claras invitaciones a la ciudadanía para que use el soporte de la Red para aproximarse a la institución. Así las cosas, y siguiendo con las afirmaciones de Javier Rojo, se aprovecharán las posibilidades que las nuevas tecnologías nos brindan a todos.

Por su parte, los solicitantes de la Comisión Especial de 1998, denominada de Estudio sobre las posibilidades y problemas de las Redes Informáticas, habían afirmado que «el espectacular desarrollo de las redes informáticas está produciendo innumerables beneficios $\mathrm{y}$, desde luego, una incipiente transformación de nuestros hábitos laborales y sociales». Asimismo, la complejidad del tema la resumían en la idea de que el espacio informático «constituye una tierra de nadie en la que ningún Estado tiene capacidad de actuar por sí solo". De igual forma se aseveraba que la posición de España en el orden mundial dependía de la acertada resolución de estos nuevos retos de la técnica. En la presentación de la web de esa Comisión se afirmaba que nos hallábamos ante una materia de interés general que ofrece «ventajas y oportunidades».

El Senado, de idéntico modo, ha estado atento a diversos eventos directamente relacionados con la Red. En este sentido, los premios del Día de Internet (25 de octubre) de 2005 se entregaron en el Senado. El senador Félix Lavilla indicó que «los objetivos del Día de Internet coinciden plenamente con los trabajos que desarrollamos desde la Comisión de la Sociedad de la Información y del Conocimiento y por ello merecen todo el apoyo del Senado ${ }^{13}$. Para ese día, desde la web del Senado se invitaba a todos los ciudadanos a participar en un chat abierto con senadores. Los promotores del Día de Internet agradecieron al Senado su labor ${ }^{14}$, a través de la siguiente declaración: «La organización del Día de Internet, en representación de las 29 asociaciones que conforman el Comité de Impulso, agradece al Senado español por albergar el acto de entrega de los Premiso Día de Internet (...) y el compromiso de esta institución con este primer proyecto en red».

13 www.el-mundo.es/navegante/2005/10/17/esociedad/1129559260.html (página consultada en noviembre de 2005).

${ }^{14}$ www.diadeinternet.es/contenidos/ (página consultada en noviembre de 2005). 
El Pleno del Senado, el 19 de octubre de 2004, aprobó una moción por la que se instaba al Gobierno a integrar los programas y acciones en materia de Sociedad de la Información y del Conocimiento, así como a presentar un nuevo Plan para el Desarrollo de la Sociedad de la Información y de Convergencia con Europa. Con base en ello se constituyó una Ponencia en el seno de la Comisión de la Sociedad de la Información y del Conocimiento, a la que nos referimos más adelante.

Igualmente, el 2 de noviembre de 2005 el Pleno del Senado aprobó por unanimidad otra moción por la que se insta al Ejecutivo a impulsar la creación de un gobierno de Internet que elabore normas para regular su funcionamiento global en todos los países. En este "gobierno", que debería estar vinculado a Naciones Unidas o a otro sistema internacional, se darían cita el sector privado, la sociedad civil, los gobiernos y la diversidad de culturas. Además, se busca que el Ejecutivo español promueva acuerdos en materia de Sociedad de la Información y del Conocimiento que permitan avanzar en cohesión social y territorial en todos los países, sobre todo en los menos desarrollados. Por último, se reclama que en el progreso en la Red se haga valer «la libertad y el respeto a los derechos humanos», especialmente, de nuevo, en los países menos desarrollados, «para incrementar su nivel de desarrollo socio-económico".

Detrás de esta moción detectamos un evidente recelo hacia el ICAAN y hacia el control que sobre el mismo ejerce Estados Unidos, aunque bien es verdad que dicho organismo ha hecho considerables esfuerzos para mantener la independencia, como lo prueba el excelente funcionamiento de Internet. Como es sabido, las conclusiones de la Cumbre Mundial para el Desarrollo de la Sociedad de la Información, celebrada en Túnez, no siguen la vía sugerida por nuestro Senado, tal vez un poco anticuada.

Estas ideas y medidas, en suma, se enmarcan dentro del deseo de reactivar el Senado como foro válido para la comunidad sociopolítica española, recuperando viveza y protagonismo (o consiguiéndolo por primera vez).

Las comisiones que han existido en el Senado sobre el tema que nos ocupa merecen que abramos un apartado nuevo.

\section{INFORMES Y COMISIONES}

En el Senado español se han venido realizando desde hace años trabajos sobre la particular problemática de Internet. En este sentido 
merecen destacarse dos comisiones que han estudiado directamente los temas de la Red. Una fue la "Comisión Especial de estudio sobre las posibilidades y problemas de las Redes Informáticas", que se creó el 24 de marzo de 1998 (eran la época de la VI Legislatura). La otra es la actual Comisión «De la Sociedad de la Información y el Conocimiento", que aparece en la VII Legislatura y que continúa existiendo en la presente VIII Legislatura.

La «Comisión Especial de Estudio sobre las posibilidades y problemas de las Redes Informáticas» (que popularmente se conoció como "Comisión de Internet», y que en los trabajos se simplificó como "Comisión Especial sobre Redes Informáticas») desarrolló su labor entre el 24 de marzo de 1998 y el 18 de diciembre de $1999^{15}$. Un mes antes de su creación en marzo de 1998 una Moción del Pleno había previsto su formación para estudiar los problemas que "plantean y pueden plantear en el futuro el desarrollo y la universalización de las redes informáticas» en los ámbitos político, jurídico y social. Con esta Comisión se pretendía incorporar a España al proceso de reflexión política en la materia, tal y como ya ocurría en otros países. Se buscaba un análisis en profundidad de una materia calificada, como se ha dicho antes, de interés general. Entre los fines que se perseguían estaba el de promocionar las ventajas y oportunidades que ofrece el desarrollo tecnológico. Para dar ejemplo, la propia Comisión aplicó estas nuevas posibilidades a su propia labor parlamentaria. La actividad de la misma se esperaba que fuera ejemplo para abordar otros trabajos y estudios que se realizan en la Cámara Alta ${ }^{16}$.

Esta Comisión tuvo 37 sesiones en las que se produjeron 55 comparecencias. El Informe final de la misma, ya citado más arriba, lo aprobó el Pleno del Senado el 17 de diciembre de 1999 (Boletín Oficial de las Cortes Generales, núm. 812, 27 de diciembre de 1999). Este Informe pretendía diagnosticar la situación en ese momento y su evolución futura. En él se reconoce que las nuevas tecnologías de la información «transforman de forma sustancial la economía, las re-

${ }^{15}$ Un análisis de sus trabajos puede verse en nuestro artículo «La labor de la Comisión Especial del Senado español sobre Redes Informáticas con relación al derecho a la intimidad», Revista de las Cortes Generales, núm. 49, 2000, págs. 259 y ss.

16 Javier DE ANDRÉS afirma que «no se conocen muchas obras donde aparezcan estudios que analicen el fenómeno sociológico de Internet desde una perspectiva tan amplia como la que aquí (en la Comisión) se pretende». Y añade: "Continuamente aparecen un gran número de ideas y opiniones en los medios de comunicación, en las news, en las listas de distribución, etc., pero no se conocen muchos estudios sistematizados como el que pretende llevar a cabo la Comisión del Senado» (www.epitelio.org/cuenca/encuentros/senado.htm, consulta en noviembre de 2005). 
laciones humanas, la cultura y la política de nuestra sociedad». Sus conclusiones más destacadas son las siguientes: todas las personas tiene el derecho fundamental de acceder libremente a la Red, sin discriminación de sexo, condición, características físico-psíquicas, edad o lugar de residencia; la libertad es una condición inherente a la Red (de acceso, circulación, información y comunicación); el ordenador personal y el domicilio electrónico son inviolables, ninguna entrada o registro podrá hacerse sin consentimiento del titular o resolución judicial, salvo en caso de flagrante delito; se garantiza el secreto de las comunicaciones electrónicas y la privacidad de los datos; es necesario la existencia de un sistema público que garantice la seguridad informática apoyando las iniciativas de autorregulación; todos los españoles tienen el derecho a la educación y a la formación en nuevas tecnologías; se promoverá la extensión de la fibra óptica; y se salvaguardará los derechos correspondientes a la propiedad intelectual e industrial. Como se ve, temas todos de amplio calado.

La Comisión tuvo una página web dentro de la página del Senado, que tenía «la intención de abrir los trabajos de la Comisión a todos los ciudadanos interesados». Actualmente está página aún está disponible en la dirección www.senado.es/comredinfl. En ella se puede ver su composición, actividad y publicaciones relacionadas con la misma, además de las opiniones vertidas en el Foro Público, foro que lógicamente ya no se encuentra activo en esa página. Este Foro Público, precedente de los que actualmente existen en el Senado, se creó para que cualquier persona opinase sobre el tema. El foro estaba dividido en seis apartados: la Red (contenido general), en donde se vertieron 315 opiniones; aspectos políticos, que registró 69 opiniones; aspectos económicos, 42 opiniones; aspectos laborales, 26 opiniones; aspectos jurídicos, 40 opiniones; y cultura de la Red (salud, convivencia, educación), 62 opiniones. En el Informe final se valora de manera muy positiva esta experiencia de la página web y se señala que supuso la introducción del primer supuesto de Parlamento electrónico en nuestro país.

Esta Comisión analizó un elevado número de temas relacionados con Internet (derecho a la intimidad, datos personales, cookies, elaboración de perfiles, criptografía, sistemas de filtrado y bloqueo, libertad de expresión, listas blancas y negras, etiquetado, seguridad, etc.). Quizá demasiados, lo que dio lugar a una labor que no fue exhaustiva en casi ninguno de los puntos tocados. La forma de enfocar las cuestiones, casi siempre optimista, también presenta una variedad similar al encontrase aproximaciones jurídicas, filosóficas, so- 
ciológicas, económicas y técnico-informáticas. Esta manera de enfocar la cuestión, desde la generalidad y heterogeneidad, dio lugar a que no se entrara en los aspectos polémicos ni que se marcara una pauta clara en ellos que sirviese de recomendación a los agentes implicados. Lo que sí se fija con precisión es la necesidad de garantizar el acceso de todos los ciudadanos a la Red. La universalización de dicho acceso debe ser garantizada, auspiciada y protegida por los poderes públicos. Es obligación del legislador español «diseñar los mecanismos para poner al servicio de la inmensa mayoría de los ciudadanos y ciudadanas las ventajas, los avances y los progresos que las nuevas tecnologías de la información ofrecen ${ }^{17}$.

La otra comisión que mencionábamos es la Comisión permanente no legislativa «De la Sociedad de la Información y el Conocimiento". Esta Comisión aparece en la anterior Legislatura (la VII), constituyéndose el 10 de mayo de 2000 con la pretensión de sustituir a la «Comisión Especial sobre Redes Informáticas». Estamos ante un órgano permanente, lo que cambia bastante el planteamiento con relación a la «Comisión Especial» puesto que supone asumir Internet como un tema que debe estar presente en el Senado de manera constante. Su principal objetivo, en palabras de la presidenta de esta Comisión en la VII Legislatura, Mercedes Coloma, es «debatir en profundidad y hacer un análisis pormenorizado de los sectores que conforman la Sociedad de la información y sus consecuencias en la vida de los ciudadanos, para luego presentarlos al gobierno (...) y hacer que la sociedad española los conozca " ${ }^{18}$.

En la VII Legislatura la Comisión realiza sus trabajos del 10 de mayo de 2000 al 20 de enero de 2004. En su balance cuenta con 45 sesiones celebradas, 3 preguntas orales en comisión (dos de ellas agrupan 113 y 174 preguntas), 2 solicitudes de informes a órganos de la Administración del Estado, 1 solicitud de informe a órganos de otras entidades públicas, 8 comparecencias de miembros del Gobierno, 28 comparecencias de autoridades y funcionarios, y 54 comparecencias de otro tipo. Su Foro Público recibió 3611 opiniones.

Asimismo, hubo una Ponencia de Estudio de los derechos de concursantes y audiencia en relación con concursos, juegos y apuestas. El Informe de esta ponencia se aprobó por la Comisión el 9 de junio de 2003 (Boletín Oficial de las Cortes Generales, Senado, Serie I,

17 Cita extraída del Informe final de la Comisión (BOCG, núm. 812, 27 de diciembre de 1999, pág. 46).

${ }^{18}$ www.idg.es/iworld/articulo.asp?id=113035 (consulta en noviembre de 2005). 
núm. 677, 13 de junio de 2003) y por el Pleno del Senado el 1 de julio del mismo año (Boletín Oficial de las Cortes Generales, Senado, Serie I, núm. 689, 1 de julio de 2003).

Además, se registraron tres mociones, a saber: Moción por la que se insta al Gobierno a que las aplicaciones informáticas de la Administración del Estado estén disponibles para diversos sistemas operativos, entre ellos Linux, y no exclusivamente para Windows; Moción por la que se insta a la creación, en el seno de la Comisión de la Sociedad de la Información y del Conocimiento, de una ponencia o grupo de trabajo para analizar, a la mayor brevedad posible, las causas que provocan el bajo uso de Internet en España y para proponer medidas para combatir tal atraso; y Moción por la que se insta al Gobierno a crear, antes de la finalización de la Legislatura, el Consejo Superior de Medios Audiovisuales en colaboración con los organismos similares que existan en la Comunidades Autónomas.

En la presente Legislatura (la VIII) esta Comisión se constituyó el 12 de mayo de 2004, formando parte de la misma 26 senadores. Hasta el 22 de junio de 2006 se habían celebrado 31 sesiones. Las iniciativas tramitadas han sido de momento las siguientes: 1 ponencia de estudio, 10 nociones, 140 preguntas orales, 2 comparecencia de miembros del Gobierno, 20 comparecencias de autoridades y funcionarios, y 46 comparecencias de otro tipo. Las iniciativas en tramitación (agosto de 2006) son: 2 comparecencias de miembros del Gobierno, 2 comparecencias de autoridades y funcionarios, y también 8 comparecencias de otro tipo. De igual forma se están tramitando 3 mociones: una, por la que se insta al Gobierno a ubicar la sede del futuro Consejo del Audiovisual en la ciudad de Barcelona; otra, por la que se insta al Gobierno a nombrar, con la mayor celeridad posible, al Director del Proyecto Integrado de Interconexión de Recuros Informáticos (RedIRIS), así como a convocar una nueva reunión del Comité Asesor de dicho proyecto para estudiar la renovación del contrato de servicios de red que cubra las necesidades de futuro y la viabilidad de descentralizar la ubicación de los enlaces internacionales que garantice el funcionamiento de la red en caso de catástrofe; y la tercera, por la que se insta al Gobierno a desarrollar un plan de actuación en el que se especifiquen las medidas necesarias para extender el uso del español en Internet. El Foro público de la Comisión en esta Legislatura ha recibido 43 opiniones hasta el 24 noviembre de 2005. Toda persona puede participar en él, la única limitación consiste en que no serán difundidas las opiniones que vulneren los principios constitucionales o lo dispuesto en el Código Penal. 
En el seno de la actual Comisión se constituyó, el 25 de mayo de 2005, una Ponencia sobre el Plan para el Desarrollo de la Sociedad de la Información y de Convergencia con Europa. Dicha Ponencia aprobó su Informe el 14 de junio de 2005 (Boletín Oficial de las Cortes Generales, Senado, Serie I, núm. 255, 16 de junio de 2005) en el que se recogen las propuestas relativas a dicho Plan. En el Informe se vuelve a subrayar de manera nítida la importancia de las nuevas tecnologías: «Avanzar en la modernización de España exige seguir apostando decididamente por las tecnologías de la información y comunicación». Las conexión socioeconómica resulta evidente: «Hoy la Sociedad del Conocimiento y el crecimiento económico no son posibles sin un pleno desarrollo de la Sociedad de la Información, que actúa como elemento de desarrollo social y bienestar para todos, y permite la difusión del conocimiento a un menor coste y un acceso de todos los ciudadanos a la información, a nuevas oportunidades y a una mayor calidad de vida». El Plan de Convergencia debería partir del objetivo de conseguir que las nuevas tecnologías formen parte de la vida cotidiana de los ciudadanos y de las empresas, asegurando la igualdad de oportunidades. Las bases de actuación en tal Plan radican en un compromiso firme del Gobierno en el tema, en una serie de elementos básicos ${ }^{19} \mathrm{y}$ ejes prioritarios ${ }^{20}$, y en la garantía de recursos económicos y materiales suficientes. A su vez, se recomiendan diversas medidas concretas que debe contener el Plan de Convergencia, entre ellas: acuerdos con las Comunidades Autónomas para favorecer el impulso de la Sociedad de la Información en la educación, convertir la administración electrónica en motor de cambio de una sociedad avanzada, la plena incorporación de las TIC a las empresas, el fomento de la seguridad, las nuevas tecnologías al servicio de las personas con discapacidad, y asegurar el seguimiento del Plan.

Para la elaboración del Informe de esta Ponencia se celebraron 17 sesiones a las que asistieron 44 comparecientes, que procedían del

19 Esos elemento básicos pasan por ser un plan de consenso, por la plena consolidación de la cohesión social y territorial que evite la brecha digital, por tener una forma clara de ejecutarlo, por ser un plan respetuoso con las competencias de las Comunidades Autónoma y de otras administraciones, por la implicación de las Cortes Generales y por impulsar las prioridades marcadas en la iniciativa europea i 2010.

${ }^{20}$ Entre ellos, la accesibilidad y universalización como un derecho ciudadano, la adaptación a la nueva era digital favoreciendo el cambio cultural, la garantía de un marco jurídico que asegure un mercado en competencia, el desarrollo de infraestructuras de banda ancha, la priorización del ámbito educativo, la promoción de la seguridad y confianza, la salvaguarda de la libertad de expresión, y la coordinación entre la Administración General del Estado, las Comunidades Autónomas y las corporaciones locales. 
poder público central y autonómico, de asociaciones de usuarios y de empresas, de empresas del sector de las telecomunicaciones, de empresas del sector audiovisual, de agentes sociales y de universidades. En estas comparecencias se insistió en la necesidad de que las tecnologías estén al servicio de la ciudadanía y en cuidar la parcela de la innovación para enfrentarse a un mundo cada vez más variable. Asimismo, se afirmó que el conjunto de España, con la coordinación de las administraciones, debe buscar un mayor crecimiento de las tecnologías de la información "para crecer, ahora que estamos todavía a tiempo, más que los demás si queremos alcanzarles en un rápido proceso de convergencia, sin olvidar la cohesión social y territorial interna de nuestro país que evite desequilibrio internos». En el concreto campo de la Administración Electrónica, los expertos señalaron que debe ser multicanal, centrada en el ciudadano, un motor para la mejora de los procesos administrativos, una herramienta para la coordinación entre administraciones y una palanca para el desarrollo de la Sociedad de la Información.

\section{CONCLUSIONES}

El balance del papel del Senado español ante el reto de Internet es ciertamente positivo. Esta valoración adquiere más fuerza si se compara con la timidez y retraso que otros órganos públicos de nuestro país han mostrado en este tema. Su actitud puede servir de ejemplo con relación al papel que los poderes públicos deben jugar en la Sociedad de la Información. El Senado ha asumido ese papel indicado anteriormente que le corresponde desempeñar al poder público ante el fenómeno de Internet.

Los hipotéticos riesgos de un parlamento electrónico (banalización o saturación, por ejemplo) no se han detectado hasta el momento. Las medidas adoptadas por la Cámara Alta en este sentido, aunque mejorables, son adecuadas para que la misma desempeñe un rol beneficioso en el conjunto del proceso político. El Senado, así, se podrá enfrentar mejor el siempre complejo proceso de toma de decisiones, al reto de la búsqueda de legitimidad en el siglo XXI y a la función que está llamado a cumplir en cuanto cámara de representación territorial.

Sin embargo, el juicio positivo que amerita la institución en el tema que ahora nos concierne debe ser matizado al menos en un doble sentido. Por un lado, todavía no se han alcanzado, ni mucho menos, todas las potencialidades que la buena predisposición del 
órgano permite prever que se pueden alcanzar (y en ello la falta de una adecuada socialización digital de la ciudadanía debe tenerse muy presente). Y, por otro lado, un elevado número de senadores semeja que no están respondiendo como lo hace el órgano ${ }^{21}$. Al margen de ello, también palpita un exceso de confianza y optimismo respecto a las nuevas tecnologías que puede hacer pasar inadvertidos los peligros que conllevan. La "euforia de la técnica» no es útil para resolver satisfactoriamente los problemas que ésta plantea.

En definitiva, la democracia se ve sometida con Internet a nuevos desafíos y posibilidades, que conllevan tanto riesgos como ventajas, aunque la valoración final resulta positiva en términos de pluralismo y participación. La diversidad interactiva, las múltiples posibilidades de conformación del usuario, las continuas alternativas, la participación en libertad o la posición igualitaria son algunas de las notas que nos permiten ser optimistas ante el futuro que nos presenta la Red en este campo.

No obstante, y pese a los avances, el proceso de redefinición a la que se han visto sometidas las asambleas representativas sigue abierto. A los juristas nos compete seguir atentos y aportar claves explicativas que permitan coronar con éxito esta transformación. El camino trazado por el Senado español está siendo un ejemplo a tener muy en cuenta aunque el destino final sea todavía incierto.

${ }^{21}$ Para realizar este trabajo contactamos por correo electrónico con los integrantes de la Comisión «De la Sociedad de la Información y del Conocimiento» con el objeto de que comentaran lo que estimasen oportuno sobre el tema. Contestaron tan sólo la quinta parte. Incluso dos de ellos carecen de cuenta de correo electrónico en el Senado (sic!). 